\title{
Design Studies of Ultra-Wideband Microstrip Antennas with a Small Capacitive Feed
}

\author{
Veeresh G. Kasabegoudar, Dibyant S. Upadhyay, and K. J. Vinoy
}

Received 29 May 2007; Accepted 10 October 2007

Recommended by James Becker

\begin{abstract}
The design of an ultra-wideband microstrip patch antenna with a small coplanar capacitive feed strip is presented. The proposed rectangular patch antenna provides an impedance bandwidth of nearly $50 \%$, and has stable radiation patterns for almost all frequencies in the operational band. Results presented here show that such wide bandwidths are also possible for triangular and semiellipse geometries with a similar feed arrangement. The proposed feed is a very small strip placed very close to the radiator on a substrate above the ground plane. Shape of the feed strip can also be different, so long as the area is not changed. Experimental results agree with the simulated results. Effects of key design parameters such as the air gap between the substrate and the ground plane, the distance between radiator patch and feed strip, and the dimensions of the feed strip on the input characteristics of the antenna have been investigated and discussed. As demonstrated here, the proposed antenna can be redesigned for any frequency in the L-, S-, C-, or X-band. A design criterion for the air gap has been empirically obtained to enable maximum antenna bandwidth for all these operational frequencies.
\end{abstract}

Copyright (c) 2007 Veeresh G. Kasabegoudar et al. This is an open access article distributed under the Creative Commons Attribution License, which permits unrestricted use, distribution, and reproduction in any medium, provided the original work is properly cited.

\section{INTRODUCTION}

Microstrip antennas (MSAs) are widely preferred for wireless communication systems that typically require antennas with small size, light weight, low profile, and low cost, and that are easy to fabricate and assemble [1]. However, basic geometries of these antennas suffer from a small bandwidth, which is of the order of a few percent of the operational frequency. In order to increase the rate of data transfer, modern wireless system designs call for increased antenna bandwidth than these geometries can handle. To meet these demands, several schemes have been suggested in recent years for the design of printed antennas with large bandwidths. Many such antennas have very good bandwidths, but have bidirectional patterns which decrease the gain [2-5]. On the other hand, MSAs have also been modified to meet the demands of the modern wireless communication applications [6] by several broadbanding techniques.

Popular broadbanding techniques used in microstrip antennas include the use of thick and air filled substrates, employing parasitic elements either in coplanar [7] or stacked configurations [8]. Use of parasitic element in coplanar configurations increases the overall size of antenna and hence limits their use. Other approaches include cutting slots inside the regular MSA geometries [9] or changing the shape of the
MSA to a diamond shape [10]. Typically, aperture and electromagnetic coupling methods of feeding are used in stacked configurations to avoid the spurious radiations from the feed network while improving the impedance bandwidth.

The coaxial probe feed is the most popular one for electrically thick substrates; but the inductance of the probe may create the impedance mismatch which can be compensated by cutting slots on the patch, modifying the probe shape, or by introducing a capacitive feed strip [11]. Yet these configurations cause alignment issues while assembling and hence may increase the production cost. The antenna reported in [11] offers less than $30 \%$ bandwidth. Several innovative feeding techniques have also been suggested to improve the bandwidth which included modification to a meandered probe feed [12]. Such three-dimensional feed arrangements are usually difficult to realize in a consistent manner. It may be pointed out that the primary advantage of MSAs lies in their ease of fabrication by standard lithography techniques.

On the other hand, the antenna proposed in [13] uses a probe fed semicircular strip proximity coupled to a flowershaped microstrip patch to provide a wide bandwidth of 63\%. Rafi and Shafai [14] reported a broadband stacked microstrip patch antenna with a V-slot which has a bandwidth of $54 \%$. Though the bandwidth values reported by $[13,14]$ are more than $50 \%$ of these use multiple metal-dielectric 


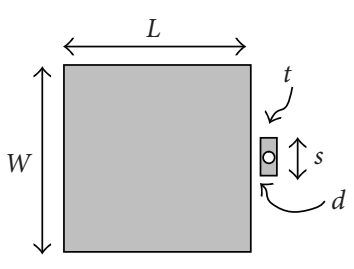

(a) Top view

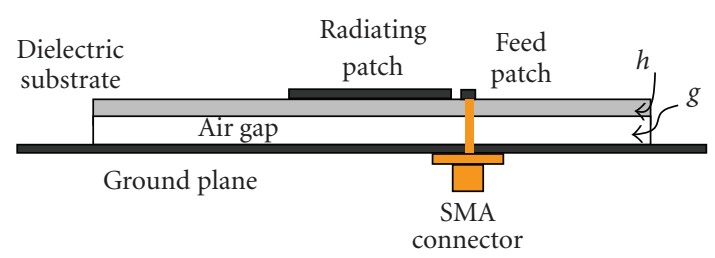

(b) Cross-sectional view

FIGURE 1: Geometry of a rectangular patch antenna with a small capacitive feed arrangement.

layers in stacked configurations which makes it difficult for fabrication and assembly. On the other hand, single-layer annular ring and circular and rectangular microstrip antennas with simple capacitive feed, offering a bandwidth upto $28 \%$, are also reported [15]. In this antenna the radiator patch and a smaller feed patch (rectangular) are located on the same plane and the antenna substrate was located above the ground plane with an air-gap separation.

In the proposed antenna we use a configuration which appears like that in [15], but resulting in substantially higher bandwidth. The capacitive feed strip in the proposed antenna is optimized to a set of much smaller dimensions compared to those used in earlier works to improve the bandwidth and to reduce spurious radiations. Furthermore, this feed approach works well with conventional geometries such as rectangular and triangular patches and offers the impedance bandwidth close to $50 \%$ in all cases studied. It may be recalled that the Federal Communications Commission (FCC) report and order (R\&O), issued on February 2002 [16], classifies ultra-wideband devices as ones having a $-10 \mathrm{~dB}$ fractional bandwidth of at least $0.2(20 \%)$ in the range of 3.110.6 GHz. After introducing the basic configuration of the antenna in Section 2, we present in Section 3 a detailed parametric study on the various design aspects of such an antenna in the rectangular patch configuration. The effects of changing the shape of the radiator patches and feed strips have also been presented there. Experimental validation of a prototype is presented in Section 4.

\section{BASIC ANTENNA CONFIGURATION}

Figure 1 shows the geometry of the proposed antenna where the larger patch works as the radiator and the smaller patch serves as a feed strip which couples the energy to the radiator by capacitive means. In the basic configuration, we use rectangular patches for both radiator and feed strip. As will be shown later, these shapes can be altered with certain constraints to get similar input characteristics. The antenna
TABLe 1: Typical dimensions for the antenna designed for $5.9 \mathrm{GHz}$.

\begin{tabular}{lc}
\hline Parameter & Value \\
\hline Length of the radiator patch $(L)$ & $15.5 \mathrm{~mm}$ \\
Width of the radiator patch $(W)$ & $16.4 \mathrm{~mm}$ \\
Length of the feed strip $(s)$ & $3.7 \mathrm{~mm}$ \\
Width of the feed strip $(t)$ & $1.2 \mathrm{~mm}$ \\
Separation of feed strip from the patch $(d)$ & $0.5 \mathrm{~mm}$ \\
Air gap between substrates $(g)$ & $6.0 \mathrm{~mm}$ \\
Relative dielectric constant $\left(\varepsilon_{r}\right)$ & 3.0 \\
Thickness of substrate $(h)$ & $1.56 \mathrm{~mm}$ \\
\hline
\end{tabular}

substrate is placed above the ground plane at a height (air gap). As will be shown in Section 3, this height plays a key role in maximizing the bandwidth one can obtain. The substrate used for antenna fabrication is an RO3003 with dielectric constant $=3$, loss tangent $=0.0013$, and thickness $h=1.56 \mathrm{~mm}$.

A typical prototype antenna is designed for the operational frequency of $5.9 \mathrm{GHz}$ based on the formulae available in standard text books $[6,17]$. The quasistatic value of effective permittivity of the two-layer configuration is found as 1.172 from expressions available in [18]. A typical set of dimensions for the antenna design are listed in Table 1. These dimensions are also used to fabricate the prototype of the antenna presented in Section 4. First, the effects of key design parameters on the return loss and bandwidth of this antenna are investigated below by numerical simulations.

\section{EFFECTS OF KEY DESIGN PARAMETERS ON ANTENNA PERFORMANCE}

In the present study, we used a very small strip placed very close to the radiator and retained the basic configuration of [15] with a substrate above the ground plane and an air gap between them. We further show that by properly choosing the size of feed strip, by separation between this and the radiator patch and the height of the air gap, the impedance bandwidth can be significantly improved (to $~ 50 \%$ ).

As noted in the previous section, the radiating rectangular patch can be designed using standard formulae for any desired resonant frequency. Key design parameters, which can be used to maximize the bandwidth of this antenna, are the air gap $(g)$ at which the antenna substrate is located above the ground plane, the distance between radiator patch and the feed strip $(d)$, and the feed strip dimensions ( $t$ and $s$ ). At this stage, it may be noted that although we have extensively studied the effect of dimensions of a rectangular feed strip, its shape can also be changed. We have also investigated the effect of the shape of the radiating patch itself under the proposed feed scheme. In the following subsections, we examine the effects of these parameters on the antenna performance. All simulations are carried out using IE3D v. 12.0 which is a method of moments (MoMs) based, electromagnetic (EM) software. 
TABLE 2: Design parameters for various curves presented in Figure 2 showing the effects of the air gap on the antenna bandwidth.

\begin{tabular}{|c|c|c|c|c|c|}
\hline Curve no. & $\begin{array}{l}\text { Air gap }(g) \\
\text { in } \mathrm{mm}\end{array}$ & $\begin{array}{c}\text { Width }(t) \text { of } \\
\text { feed strip }(\mathrm{mm})\end{array}$ & $\begin{array}{c}\text { Length }(s) \text { of } \\
\text { feed strip }(\mathrm{mm})\end{array}$ & $\begin{array}{l}\text { Separation }(d) \text { of } \\
\text { feed strip }(\mathrm{mm})\end{array}$ & $\begin{array}{c}\text { Bandwidth } \\
(\mathrm{GHz})\end{array}$ \\
\hline 1 & 5.0 & 2.0 & 5.5 & 0.2 & 2.71 \\
\hline 2 & 5.5 & 1.8 & 3.7 & 0.5 & 3.01 \\
\hline 3 & 5.5 & 1.2 & 4.1 & 0.5 & 3.07 \\
\hline 4 & 5.5 & 1.2 & 3.8 & 0.1 & 3.07 \\
\hline 5 & 6.0 & 1.2 & 3.7 & 0.5 & 2.99 \\
\hline 6 & 6.0 & 1.6 & 2.8 & 0.5 & 3.09 \\
\hline 7 & 6.5 & 1.2 & 3.7 & 0.5 & 2.82 \\
\hline 8 & 7.0 & 1.2 & 3.7 & 0.5 & 2.66 \\
\hline 9 & 7.5 & 1.2 & 3.7 & 0.5 & 2.46 \\
\hline
\end{tabular}

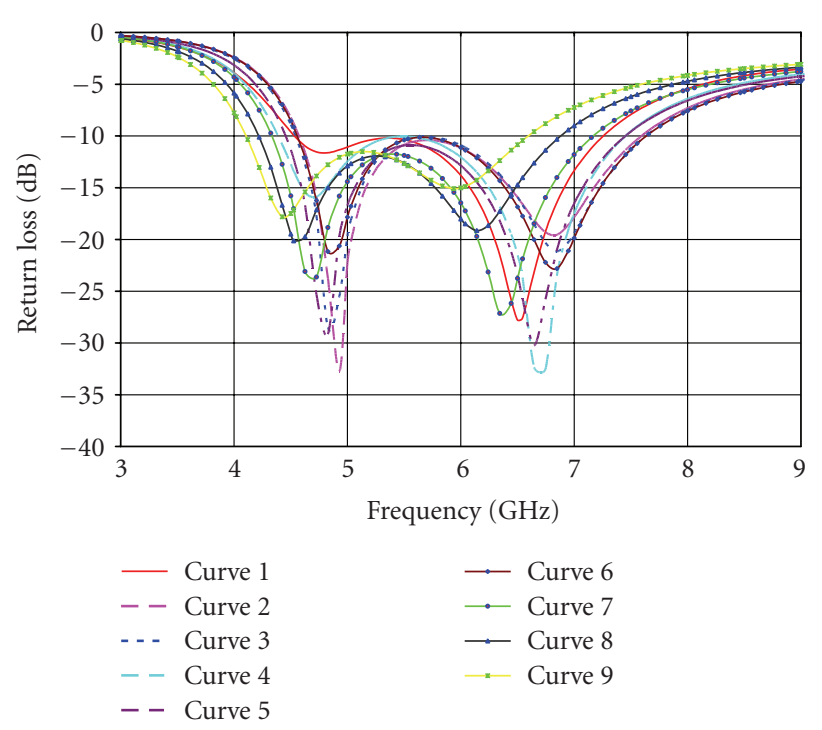

FIGURE 2: Return loss characteristics for different values of air gap. The other design parameters affected by this change are listed in Table 2. Dimensions of the radiating patch are kept constant.

\subsection{Effect of air gap $(g)$}

It is widely understood that as the effective substrate height increases or permittivity decreases, microstrip antennas result in wider bandwidth. However, in the present configuration of a nearly square patch, when two resonant frequencies are close enough these may merge to form single operational band with return loss below $-10 \mathrm{~dB}$. This may happen only for a certain range of values of " $g$." The effect of air gap on the return loss characteristics of the antenna is shown in Figure 2 and the bandwidth along with corresponding dimensions of key design parameters for each case are summarized in Table 2. One of the reasons for the antenna impedance to be dependent on the air gap is the change in inductance of the probe pin [19]. To a certain extent, this can be compensated by varying the physical parameters $(d, t$, and $s)$ of the feed strip. If we reduce the air gap keeping the dimensions of feed strip as in Table 1, the resulting antenna will have two separate, narrow bands of operation. To get the continuous and wide bandwidth, the antenna is redesigned with the feed strip with dimensions given in Table 2. The shift in the resonant frequency is due to the fact that when air gap increases, the effective dielectric constant changes; and this leads to change in the effective dimensions of the patch. As one would notice, an air gap of $6.0 \mathrm{~mm}$ results in the maximum bandwidth for the designed operational frequency.

It should be noted that if maximizing the bandwidth is the objective, the solutions may not be unique. As a result, the antenna performance can be reoptimized either by changing any one of the parameters. For example, when the air gap is equal to $5.5 \mathrm{~mm}$, we have three sets of values to get similar results (curve no. 2, 3, and 4). In the parameters set given in curve 2, compared to dimensions listed in Table 1, only " $t$ " is changed to $1.8 \mathrm{~mm}$, whereas in the curve 3 , " $s$ " is changed to get a better bandwidth. In curve number 4 , two parameters ( $d$ and $s$ ) are varied to get a similar response. For other values of air gap, we have changed all three parameters to obtain return loss below $-10 \mathrm{~dB}$.

Although it may appear that an air gap of $6 \mathrm{~mm}$ may be the best suited to maximize the bandwidth, this optimum air gap is true only for the present operational band. This may have to be redesigned along with the radiator patch dimensions for substantially different operational bands. Such cases have been presented in Table 3 for center frequencies of 2 , $4.5,8.0$, and $10 \mathrm{GHz}$. The corresponding return loss characteristics are plotted in Figure 3 after normalizing with respect to these center frequencies. Based on this study, we conclude that for maximizing the bandwidth, the air gap should be such that

$$
g \cong 0.16 \lambda_{c}-h \sqrt{\varepsilon_{r}},
$$

where $\lambda_{c}$ is the wavelength corresponding to the center frequency of the operating band, $h$ is the height of the substrate, and $\varepsilon_{r}$ is the relative dielectric constant of the substrate.

It may be noted that this is consistent with the literature based on $[20,21]$. These suggest that the maximum bandwidth can be obtained for electrically thick substrates whose heights are in the range of $0.14 \lambda_{d}-0.22 \lambda_{d}$, where $\lambda_{d}$ is the operating wavelength in the medium. However, note that the data given in $[20,21]$ are for single-layer substrates. In (1), we propose a modification to this range of thickness by 
TABLE 3: Design parameters for various curves presented in Figure 3 showing that the air gap should be re-optimized for the frequency band of interest. Other design parameters are as listed in Table 1.

\begin{tabular}{|c|c|c|c|c|c|c|}
\hline Curve no. & $\begin{array}{c}\text { Design center } \\
\text { frequency }(\mathrm{GHz})\end{array}$ & $\begin{array}{l}\text { Initial air gap } \\
(g) \text { by }(1)(\mathrm{mm})\end{array}$ & $\begin{array}{l}\text { Optimum air gap } \\
\qquad(g)(\mathrm{mm})\end{array}$ & $\begin{array}{c}\text { Width }(t) \text { of } \\
\text { feed strip }(\mathrm{mm})\end{array}$ & $\begin{array}{c}\text { Length }(s) \text { of } \\
\text { feed strip }(\mathrm{mm})\end{array}$ & $\begin{array}{l}\text { Percentage } \\
\text { bandwidth }\end{array}$ \\
\hline 1 & 2.0 & 21.3 & 19.2 & 1.8 & 6.2 & 46.0 \\
\hline 2 & 4.5 & 7.96 & 7.8 & 1.2 & 5.0 & 50.3 \\
\hline 3 & 5.9 & 5.43 & 5.5 & 1.2 & 3.7 & 50.4 \\
\hline 4 & 8.0 & 3.30 & 3.5 & 1.2 & 3.7 & 54.4 \\
\hline 5 & 10.0 & 2.10 & 2.25 & 1.2 & 3.7 & 58.2 \\
\hline
\end{tabular}

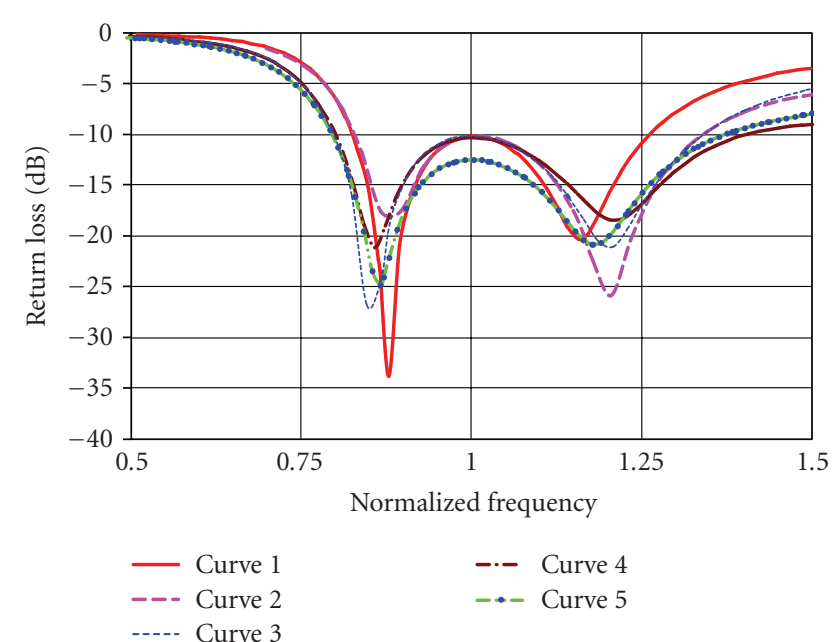

Figure 3: Normalized return loss characteristics of antennas designed for maximum bandwidth with center frequencies of 2, 4.5, 5.9, 8.0, and $10.0 \mathrm{GHz}$. The dimensions of the feed strip and the height of air gap in each case are listed in Table 3.

suggesting to use the substrate configuration as a composite material of thickness equal to $0.16 \lambda_{c}$. However, the optimum air gap for maximum bandwidth can be fine tuned by simulations from the start value given by (1). Our studies indicate that the optimum value would be within $\pm 10 \%$ of this start value given in (1). This would be acceptable since the antenna bandwidth is wide enough and does not vary much with such variations in air gap. With optimized air gap and feed strip dimensions we were able to get the impedance bandwidth close to $50 \%$ for bands of operation. It may, however, be noted that $\lambda_{c}$ in (1) does not correspond to the resonant frequency of the antenna, but it is the center frequency of the band of operation $\left(S_{11}<-10 \mathrm{~dB}\right)$.

\subsection{Effect of distance between the radiator patch and feed strip (d)}

The dimensions and location of the feed strip play a critical role in obtaining the wide bandwidth for the proposed antenna. First, we studied the effect of distance between radiator patch and the strip $(d)$ on the impedance bandwidth of antenna. Although " $d$ " has a very small effect on the bandwidth, it does change the input impedance of the antenna. The resistive part decreases and the reactive part increases

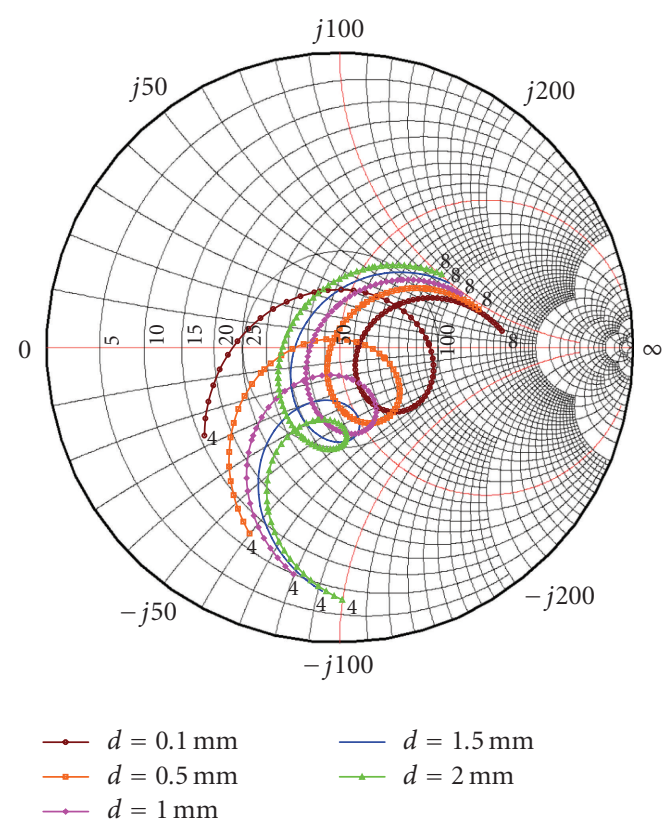

FIgURE 4: Smith chart for different distances between feed strip and radiator patch.

with an increase in the distance between feed strip and the radiator patch $(d)$. Note that this is consistent with the results reported in [15]. For $d \leq 1.0 \mathrm{~mm}$ and $d \geq 2.0 \mathrm{~mm}$, the antenna impedance exceeds VSWR $=2$ circle (reflection coefficient $=0.33$ ) as shown in Figure 4 , and the return loss characteristics curve splits into two separate bands.

\subsection{Effects of the dimensions of feed strip}

The bandwidth of antenna slightly decreases with increase in the width of the feed strip (see Figure 5) if all other parameters are kept constant; but the bandwidth of antenna can be restored to the maximum value by decreasing the feed strip length $(s)$. With the increase in strip width, the resistive part of the antenna input impedance increases, whereas the reactive part decreases. So, fine tuning of input impedance for good return loss characteristics is possible by changing the dimensions of the feed strip. In other words, impedance bandwidth can be appropriately controlled. The resulting antenna bandwidth is summarized in Table 4. Note that the width of the feed strip is not reduced below $1.2 \mathrm{~mm}$ as this 


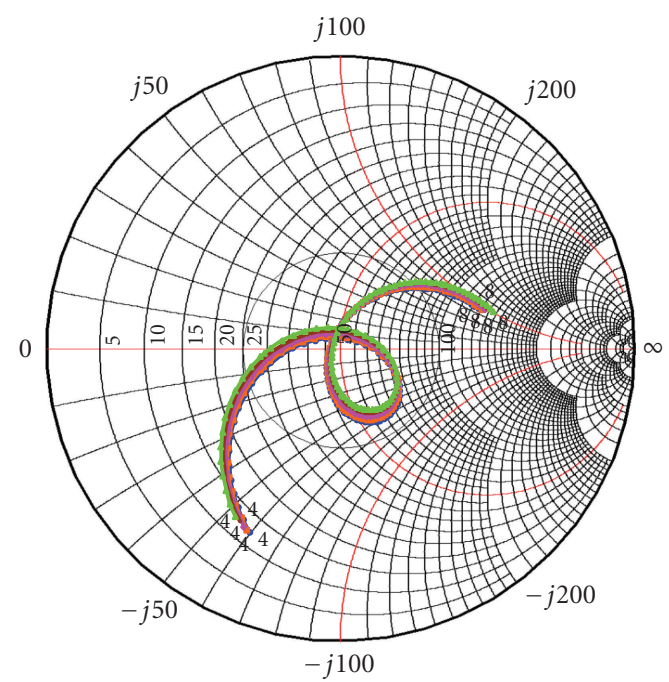

$$
\begin{aligned}
\longrightarrow t & =1.2 \mathrm{~mm} \\
\longrightarrow t & =1.4 \mathrm{~mm} \\
\longrightarrow t & =1.6 \mathrm{~mm}
\end{aligned} \quad \longrightarrow t=2 \mathrm{~mm}
$$

FIGURE 5: Smith chart for different feed strip widths plotted from 4-8 GHz.

TABLE 4: Effects of the variation of the width of the feed strip $(t)$ on the $-10 \mathrm{~dB}$ bandwidth of the antenna. Other design parameters are listed in Table 1.

\begin{tabular}{lccccc}
\hline Feed strip width $(t)$ in $\mathrm{mm}$ & 1.2 & 1.4 & 1.6 & 1.8 & 2.0 \\
\hline Bandwidth $(\mathrm{GHz})$ & 2.99 & 2.95 & 2.90 & 2.86 & 2.80 \\
\hline
\end{tabular}

TABLE 5: Effects of the variation in the length of the feed strip $(s)$ on the antenna bandwidth. Other design parameters are as listed in Table 1.

\begin{tabular}{lccccc}
\hline Feed strip length $(s)$ in $\mathrm{mm}$ & 4.2 & 3.7 & 3.5 & 3.3 & 3.1 \\
\hline Bandwidth $(\mathrm{GHz})$ & 2.95 & 2.99 & 3.01 & 3.04 & 3.08 \\
\hline
\end{tabular}

is the diameter of the pin of SMA connector. Hence, we conclude that in this case, $1.2 \mathrm{~mm}$ results in the maximum bandwidth.

As mentioned above, the bandwidth reduction caused by increasing the strip width $(t)$ can be restored to a great extent by decreasing its length. This is consistent with the bandwidth presented in Table 5. However, as shown in Figure 6, for length below $3.1 \mathrm{~mm}$ (with all other parameters kept constant) the return loss curve splits into two separate bands that is, we get two narrow resonant bands. Similar to the case with the variation of changing the feed strip width, antenna input resistance increases and the input reactance decreases with an increase in the length of the feed strip. For $s \leq 2.5 \mathrm{~mm}$, the VSWR exceeds 2 at some frequencies in the band, that is, band splits into two parts. For $s \geq 3.7 \mathrm{~mm}$, even though we get approximately the same impedance bandwidth, increasing the dimensions of the feed strip produces asymmetry in the radiation patterns (due to spurious radiation from the larger feeding patch) and results in a reduction in useful bandwidth.

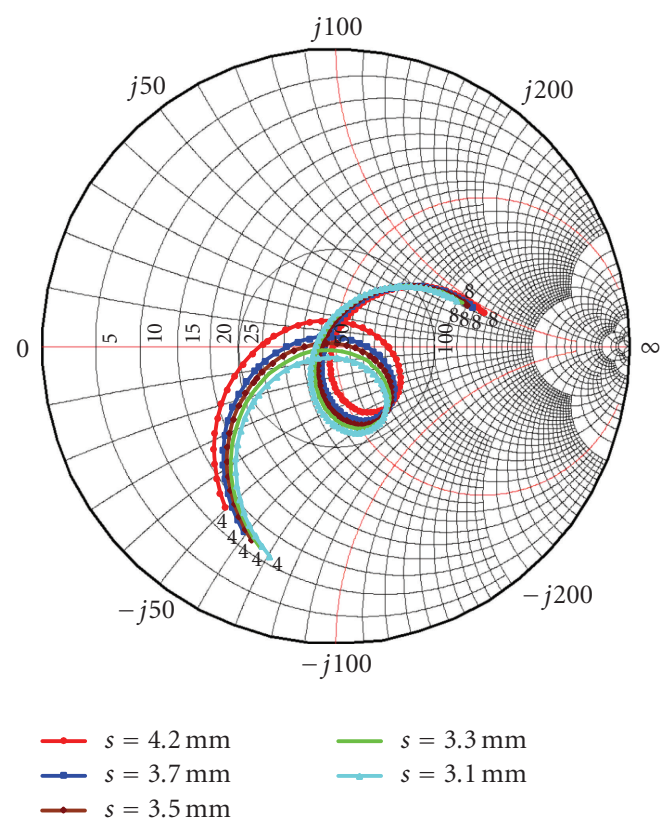

Figure 6: Impedance plot for different feed strip length.

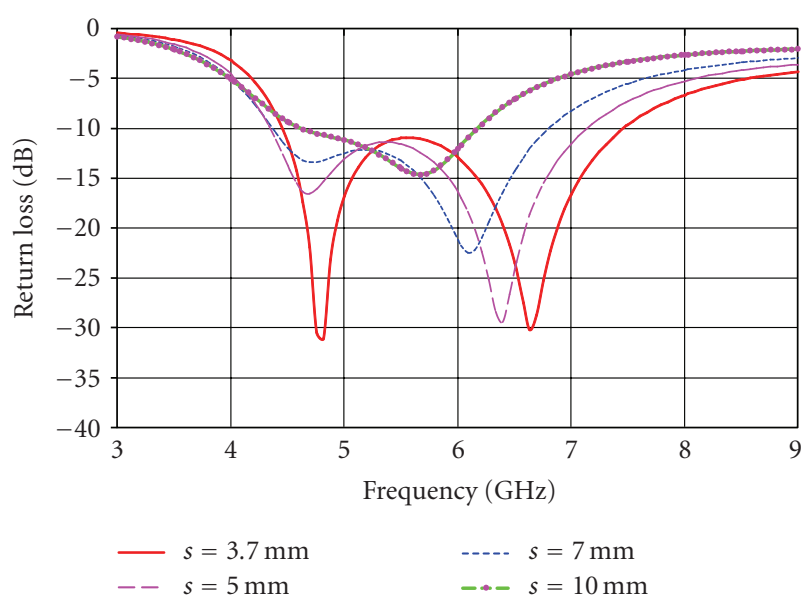

FIGURE 7: Effect of large changes in strip length on impedance bandwidth.

For significantly large values of the length of the feed strip, the return loss characteristics will be somewhat different as shown in Figure 7. The characteristics similar to those of [15] can be obtained for $s=10 \mathrm{~mm}$. From Table 6 it can be seen that the impedance bandwidth reduces drastically for the significant increase in the feed strip lengths and hence the fractional bandwidth gets smaller. Similar effect can be seen for large increase in the width of the strip, keeping the length constant. The reason for less bandwidth of the antennas reported by [15] is the use of larger feed strip dimensions which are comparable to the size of radiator patch, degrading the antenna performance (input impedance will change suddenly as the dimensions are comparable with the wavelength) and the improper air gap value. Another disadvantage of using large feed strip is the increased spurious radiation, which 
TABLE 6: Effect of a large variation in the length of the feed strip (s) on the impedance bandwidth. Other design parameters are as listed in Table 1.

\begin{tabular}{lccc}
\hline $\begin{array}{l}\text { Feed strip length }(s) \\
\text { in } \mathrm{mm}\end{array}$ & $\begin{array}{c}\text { Separation }(d) \\
\mathrm{mm}\end{array}$ & $\begin{array}{c}\text { Bandwidth } \\
(\mathrm{GHz})\end{array}$ & $\begin{array}{c}\text { Percentage } \\
\text { bandwidth }\end{array}$ \\
\hline 3.7 & 0.5 & 2.99 & 49.9 \\
5.0 & 0.5 & 2.77 & 48.0 \\
7.0 & 1.0 & 2.41 & 43.0 \\
10.0 & 2.5 & 1.52 & 28.0 \\
\hline
\end{tabular}

may cause more asymmetry in the radiation patterns at all frequencies.

The capacitance between the feed strip and the ground plane and the coupling capacitance due to the separation between the radiator patch and feed strip (d) play an important role in selecting the dimensions of the feed strip [22]. The behavior of gap capacitance due to $d$ can be modeled using the L-network model suggested in [22] or $\pi$-network equivalent given in [23]. Note that the inductive reactance offered by the probe [19] must be taken into account in the networks suggested by $[22,23]$. However, from the observations we made in our detailed parametric study, we can use the minimum values of " $d$ " and " $t$ " as $0.5 \mathrm{~mm}$ and $1.2 \mathrm{~mm}$, respectively, due to physical limitations. The strip length $(s)$ can, therefore, be the only parameter used to maximize the antenna bandwidth.

\subsection{Effect of the shape of the radiator patch}

We expect that the proposed feed scheme is flexible enough that it works well with other patch geometries. In the present study, we examined this aspect by redesigning other conventional patch geometries for the same resonant frequency as the rectangular patch and optimizing feed configurations for these. The resulting triangular patch has dimensions of $19.75 \mathrm{~mm}$ (base) and $16.5 \mathrm{~mm}$ (height). The feed is located symmetrically parallel to the base. The semiellipse geometry has its semimajor and semiminor axes as $19 \mathrm{~mm}$ and $8.23 \mathrm{~mm}$. The feed strip is located symmetrically parallel to the straight edge. The return loss characteristics are shown in Figure 8 . Since the bandwidth remains nearly the same, this feed approach may be considered to be versatile enough for use with any patch geometry.

Similar radiation patterns were obtained for rectangular, triangular, and semiellipse patch antennas. Simulated gain versus frequency plots for all three geometries are given in Figure 9. Gain of these patches is greater than $5 \mathrm{~dB}$ nearly throughout the band.

\subsection{Effect of the shape of the feed strip}

We have also investigated the effect of changing the shape of the feeding strip, and considered triangular and circular strips in addition to the rectangular feed strip used so far. Dimensions associated with the resulting geometries are tabulated in Table 7. Patch dimensions and the air gap have been kept constant. These geometries are reoptimized for the best

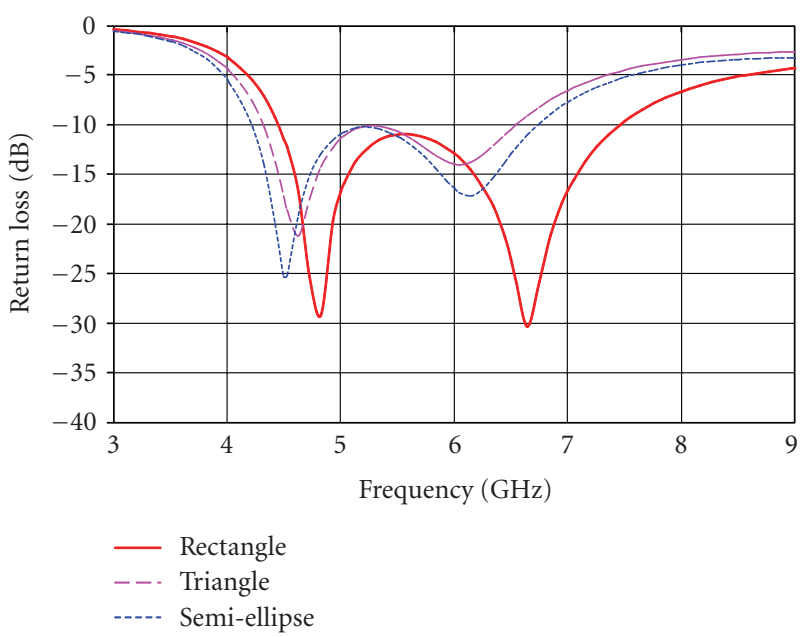

FIgURE 8: Return loss characteristics of antennas with various radiating patch geometries.

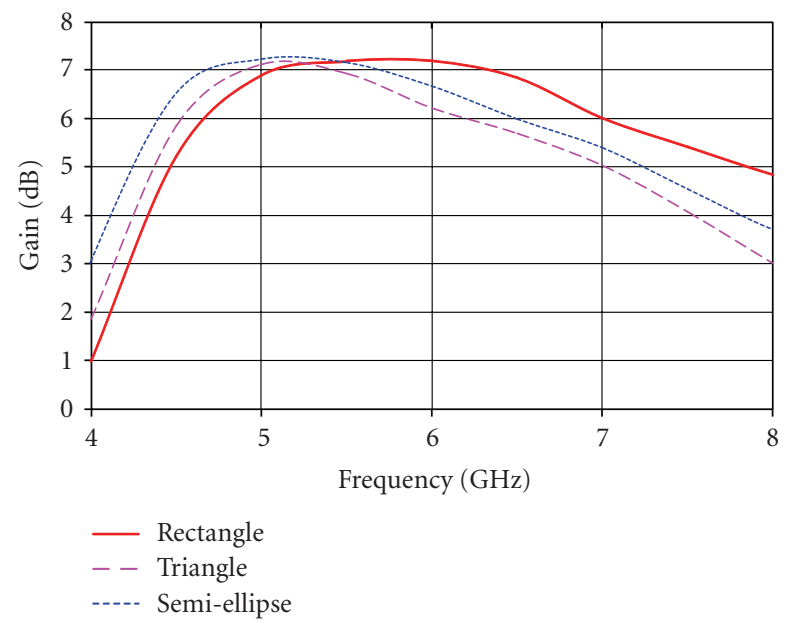

FIGURE 9: Gain versus frequency plot.

TABLE 7: Effect of changing the shape of the feed strip with rectangular radiator patch. Other design parameters are as listed in Table 1 .

\begin{tabular}{lcccc}
\hline $\begin{array}{l}\text { Shape of } \\
\text { feed strip }\end{array}$ & $\begin{array}{c}\text { Dimensions of } \\
\text { feed strip } \\
(\mathrm{mm})\end{array}$ & $\begin{array}{c}\text { Area of } \\
\text { feed strip } \\
\left(\mathrm{mm}^{2}\right)\end{array}$ & $\begin{array}{c}\text { Bandwidth } \\
(\mathrm{GHz})\end{array}$ & $\begin{array}{c}\text { Percentage } \\
\text { Bandwidth }\end{array}$ \\
\hline Rectangular & $t=1.6, s=2.8$ & 4.48 & 3.09 & 50.7 \\
Triangular & $b=3, h=3$ & 4.50 & 3.06 & 50.4 \\
Circular & $r=1.2$ & 4.52 & 2.83 & 47.0 \\
\hline
\end{tabular}

possible bandwidth. Since the capacitance of the feed strip does not change because the areas of all three shapes are nearly equal, the antenna can be expected to behave similarly. Although it has been mentioned in [24] that other shapes like circular geometry can be used in place of rectangular feed strip, we have given the criterion for choosing the dimensions so as to get maximum bandwidth. However, generalizing this 


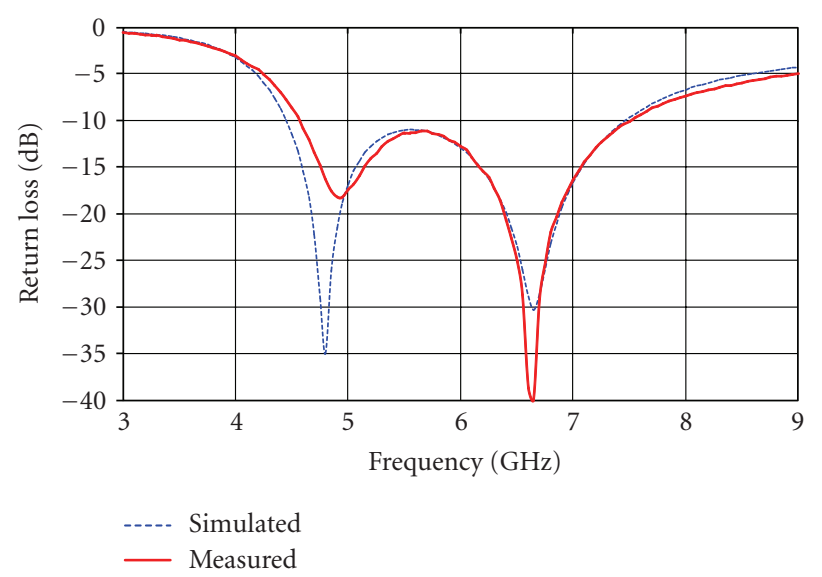

FIGURE 10: Experimental validation of the input characteristics of the antenna.

concept in the design would require further analysis of the series and shunt capacitance of the feed strip $[22,23]$.

\subsection{Discussion of simulation results}

This feed scheme has been shown to be independent of the shape of the feed strip and the radiating patch. Based on these conclusions, we now demonstrate the experimental validation for a wideband microstrip antenna. Based on the parametric studies conducted here, we conclude that a very small feed strip close to the radiating patch would result in much large bandwidth compared to that reported in [15]. Detailed parametric studies have been conducted for various design parameters. It has been found that an effective composite dielectric thickness of about $0.16 \lambda_{c}$ results in maximum bandwidth in all cases studied.

\section{EXPERIMENTAL COMPARISON}

A prototype rectangular patch antenna (see Figure 1) of dimensions listed in Table 1 is fabricated on an RT duroid substrate of dielectric constant of 3.0 and thickness of $1.56 \mathrm{~mm}$. This substrate is assembled above aluminum ground plane of dimensions of $150 \times 150 \mathrm{~mm}^{2}$. The pin of the SMA connector is extended to reach the feed patch and is soldered there. This prototype antenna was tested for $S_{11}$ using Agilent PNA (N5230A). The radiation pattern was measured in an in-house microwave anechoic chamber by a swept frequency measurement. As shown in Figure 10, the measured return loss $\left(\mathrm{S}_{11}\right)$ is better than $-10 \mathrm{~dB}(\mathrm{VSWR}<2)$ for frequencies in the range of $4.49-7.47 \mathrm{GHz}$. This corresponds to a percentage bandwidth close to $50 \%$. The slight difference between the simulated and measured results may be attributed to the infinite ground plane assumption used in the simulations and fabrication inaccuracies. The measured radiation patterns of the proposed antenna are plotted at several indicative spot frequencies within this band and are shown in Figure 11. The cross-polarization levels at the bore sight are below $-20 \mathrm{~dB}$, but degrade at other angles. The $H$-plane radiation patterns of the antenna are symmetrical at all frequen-

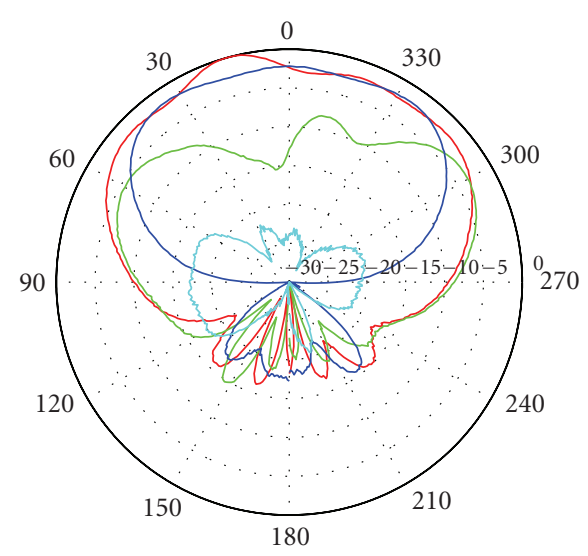

(a) Co- and cross-polarization patterns at $4.5 \mathrm{GHz}$

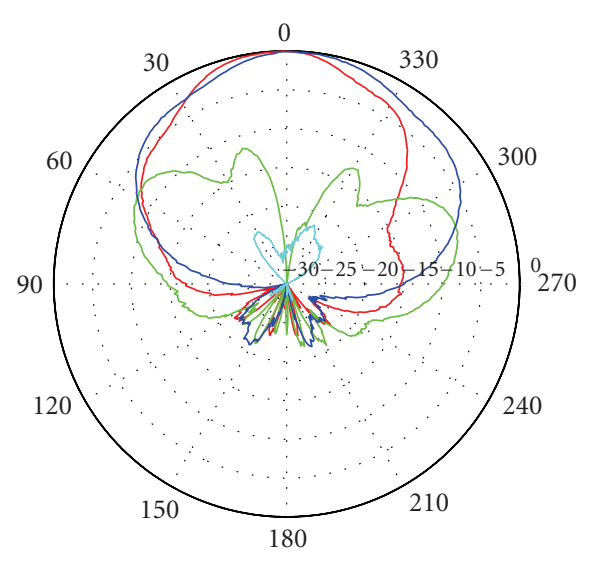

(b) Co- and cross-polarization patterns at $6.0 \mathrm{GHz}$

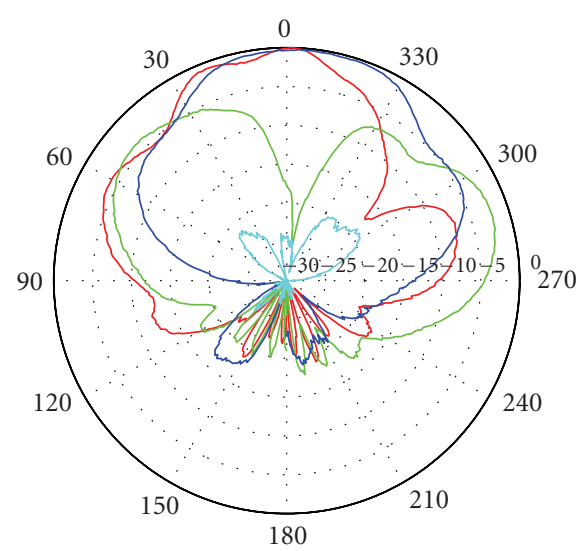

(c) Co- and cross-polarization patterns at $7.5 \mathrm{GHz}$

$$
\begin{array}{ll}
-H \text {-plane co-pol. } \quad-\quad \text {-plane cross pol. } \\
\text { E-plane co-pol. } \quad-H \text {-plane cross pol. }
\end{array}
$$

FIGURE 11: Measured radiation patterns of the ultra wideband rectangular patch antenna at selected frequency points.

cies, but there is a small asymmetry in the E-plane patterns, particularly at higher frequencies within the band. The back lobe radiations in the measured results are less than $-15 \mathrm{~dB}$ at all frequencies. 


\section{CONCLUSION}

Ultra-wideband microstrip patch antennas with a small capacitive feed are proposed here. After presenting the basic configuration involving a rectangular patch and a rectangular feed strip, the effects of all key design parameters are studied for optimum design. Return loss bandwidth (below $-10 \mathrm{~dB}$ ) of nearly $50 \%$ has been obtained for a wide range of frequencies (L-, S-, C-, and X-band), and different shapes of patches and feed strips. When the feed strip dimensions are comparable with the size of radiator patch, the antenna bandwidth appears to be less. On the other hand, the feed strip dimensions cannot be reduced below limits to avoid problems in soldering the probe pin. The antenna can be designed at any frequency to get the similar performance by selecting proper air gap value and corresponding dimensions of the MSA. The only drawback is that the feed strip causes the asymmetry in radiation characteristic at the higher frequency end but is marginal at most frequencies of interest. A selection criterion for designing the air gap for maximum bandwidth has been presented. Based on the results presented here, the proposed feed scheme is versatile and can be used for designing simpleto-fabricate wideband microstrip patch antennas.

\section{REFERENCES}

[1] R. Garg, P. Bhartia, I. Bahl, and A. Ittipiboon, Microstrip Antenna Design Handbook, Artech House, Norwood, Mass, USA, 2001.

[2] X.-C. Lin and L.-T. Wang, "A broadband CPW-fed loop slot antenna with harmonic control," IEEE Antennas and Wireless Propagation Letters, vol. 2, pp. 323-325, 2003.

[3] J.-Y. Chiou, J.-Y. Sze, and K.-L. Wong, "A broadband CPW-fed strip-loaded square slot antenna," IEEE Transactions on Antennas and Propagation, vol. 51, no. 4, pp. 719-721, 2003.

[4] H.-D. Chen, "Broadband CPW-fed square slot antennas with a widened tuning stub," IEEE Transactions on Antennas and Propagation, vol. 51, no. 8, pp. 1982-1986, 2003.

[5] N. Behdad and K. Sarahandi, "A multi-resonant singleelement wideband slot antenna," IEEE Antennas and Wireless Propagation Letters, vol. 3, no. 1, pp. 5-8, 2004.

[6] G. Kumar and K. P. Ray, Broadband Microstrip Antennas, Artech House, Norwood, Mass, USA, 2003.

[7] G. Kumar and K. C. Gupta, "Nonradiating edges and four edges gap-coupled multiple resonator broadband microstrip antennas," IEEE Transactions on Antennas and Propagation, vol. 33, no. 2, pp. 173-178, 1985.

[8] S. D. Targonski, R. B. Waterhouse, and D. M. Pozar, "Wideband aperture coupled stacked patch antenna using thick substrates," Electronics Letters, vol. 32, no. 21, pp. 1941-1942, 1996.

[9] K. M. Luk, K. F. Lee, and W. L. Tam, "Circular U-slot patch with dielectric superstrate," Electronics Letters, vol. 33, no. 12, pp. 1001-1002, 1997.

[10] G. Z. Rafi and L. Shafai, "Wideband V-slotted diamondshaped microstrip patch antenna," Electronics Letters, vol. 40, no. 19, pp. 1166-1167, 2004.

[11] G. A. E. Vandenbosch and A. R. van de Capelle, "Study of the capacitively fed microstrip antenna element," IEEE Transactions on Antennas and Propagation, vol. 42, no. 12, pp. 16481652, 1994.
[12] H. W. Lai and K. M. Luk, "Wideband stacked patch antenna fed by meandering probe," Electronics Letters, vol. 41, no. 6, pp. 297-298, 2005.

[13] B. L. Ooi and I. Ang, "Broadband semicircle-fed flower-shaped microstrip patch antenna," Electronics Letters, vol. 41, no. 17, pp. 939-940, 2005.

[14] G. Rafi and L. Shafai, "Broadband microstrip patch antenna with V-slot," IEE Proceedings: Microwaves, Antennas and Propagation, vol. 151, no. 5, pp. 435-440, 2004.

[15] G. Mayhew-Ridgers, J. W. Odendaal, and J. Joubert, "Singlelayer capacitive feed for wideband probe-fed microstrip antenna elements," IEEE Transactions on Antennas and Propagation, vol. 51, no. 6, pp. 1405-1407, 2003.

[16] "New public safety applications and broadband internet access among uses envisioned by FCC authorization of ultrawideband technology," first report and order (FCC 02-48), action by the Commission, February, 2002.

[17] C. A. Balanis, Antenna Theory, John Wiley \& Sons, Hoboken, NJ, USA, 2nd edition, 2004.

[18] I. Papapolymerou, R. F. Drayton, and L. P. B. Katehi, "Micromachined patch antennas," IEEE Transactions on Antennas and Propagation, vol. 46, no. 2, pp. 275-283, 1998.

[19] A. K. Verma, N. V. Tyagi, and D. Chakraverty, "Input impedance of probe-fed multilayer rectangular microstrip patch antenna using the modified Wolff model," Microwave and Optical Technology Letters, vol. 31, no. 3, pp. 237-239, 2001.

[20] E. Chang, S. A. Long, and W. F. Richards, "An experimental investigation of electrically thick rectangular microstrip antennas," IEEE Transactions on Antennas and Propagation, vol. 34, no. 6, pp. 767-772, 1986.

[21] K. Guney, "A simple and accurate expression for the bandwidth of electrically thick rectangular microstrip antennas," Microwave and Optical Technology Letters, vol. 36, no. 3, pp. 225-228, 2003.

[22] C.-C. Yu and K. Chang, "Transmission-line analysis of a capacitively coupled microstrip-ring resonator," IEEE Transactions on Microwave Theory and Techniques, vol. 45, no. 11, pp. 2018-2024, 1997.

[23] A. Asthana and B. R. Vishvakarma, "Analysis of gap-coupled microstrip antenna," International Journal of Electronics, vol. 88, no. 6, pp. 707-718, 2001.

[24] G. Mayhew-Ridgers, J. W. Odendaal, and J. Joubert, "Efficient full-wave modeling of patch antenna arrays with new singlelayer capacitive feed probes," IEEE Transactions on Antennas and Propagation, vol. 53, no. 10, pp. 3219-3228, 2005.

\section{AUTHOR CONTACT INFORMATION}

Veeresh G. Kasabegoudar: Microwave Laboratory, Electrical Communication Engineering department, Indian Institute of Science, Bangalore 560 012, India; veereshgk2002@rediffmail.com

Dibyant S. Upadhyay: Microwave Laboratory, Electrical Communication Engineering department, Indian Institute of Science, Bangalore 560 012, India; dibyant_e@yahoo.com

K. J. Vinoy: Microwave Laboratory, Electrical Communication Engineering department, Indian Institute of Science, Bangalore 560 012, India; kjvinoy@ece.iisc.ernet.in 

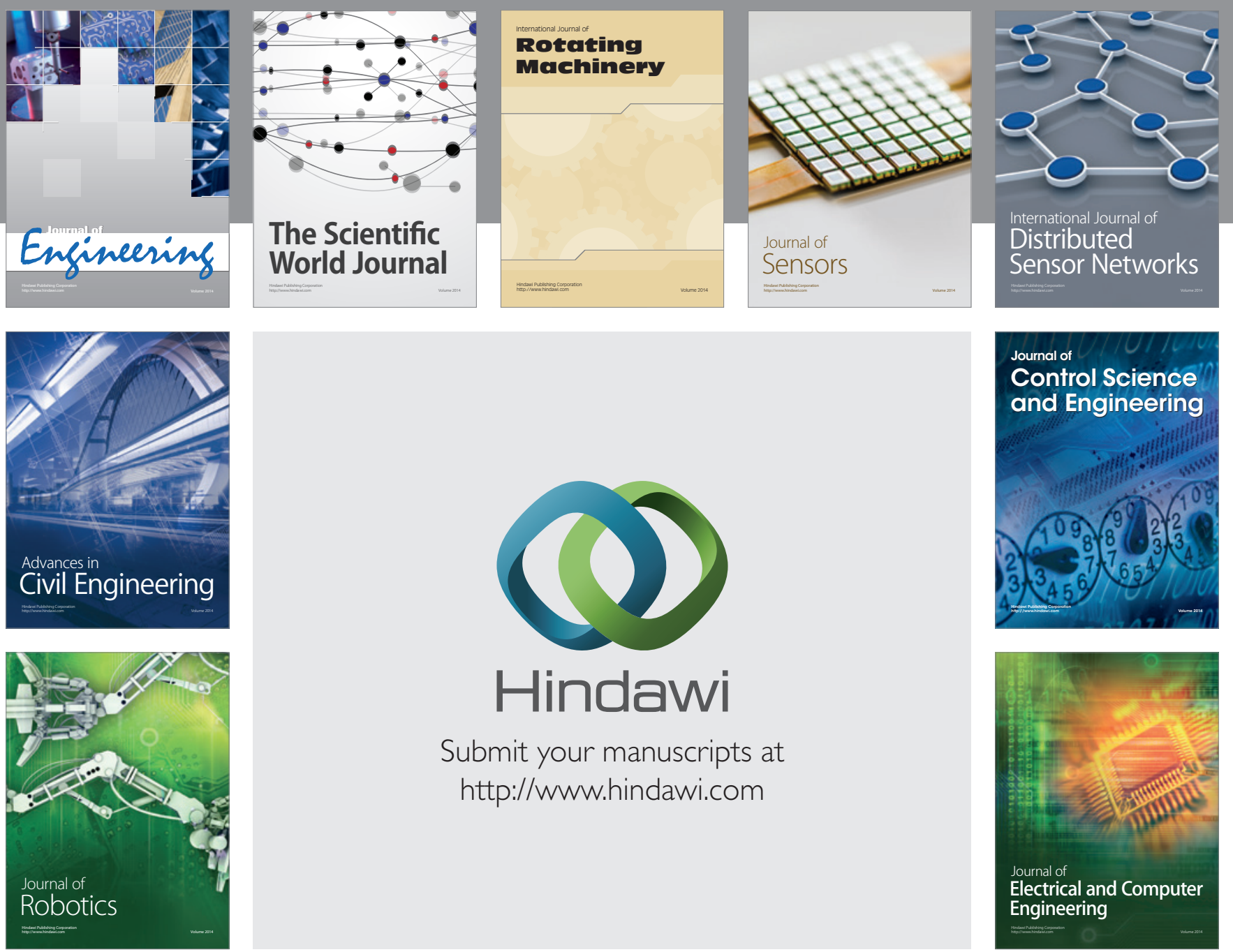

Submit your manuscripts at

http://www.hindawi.com
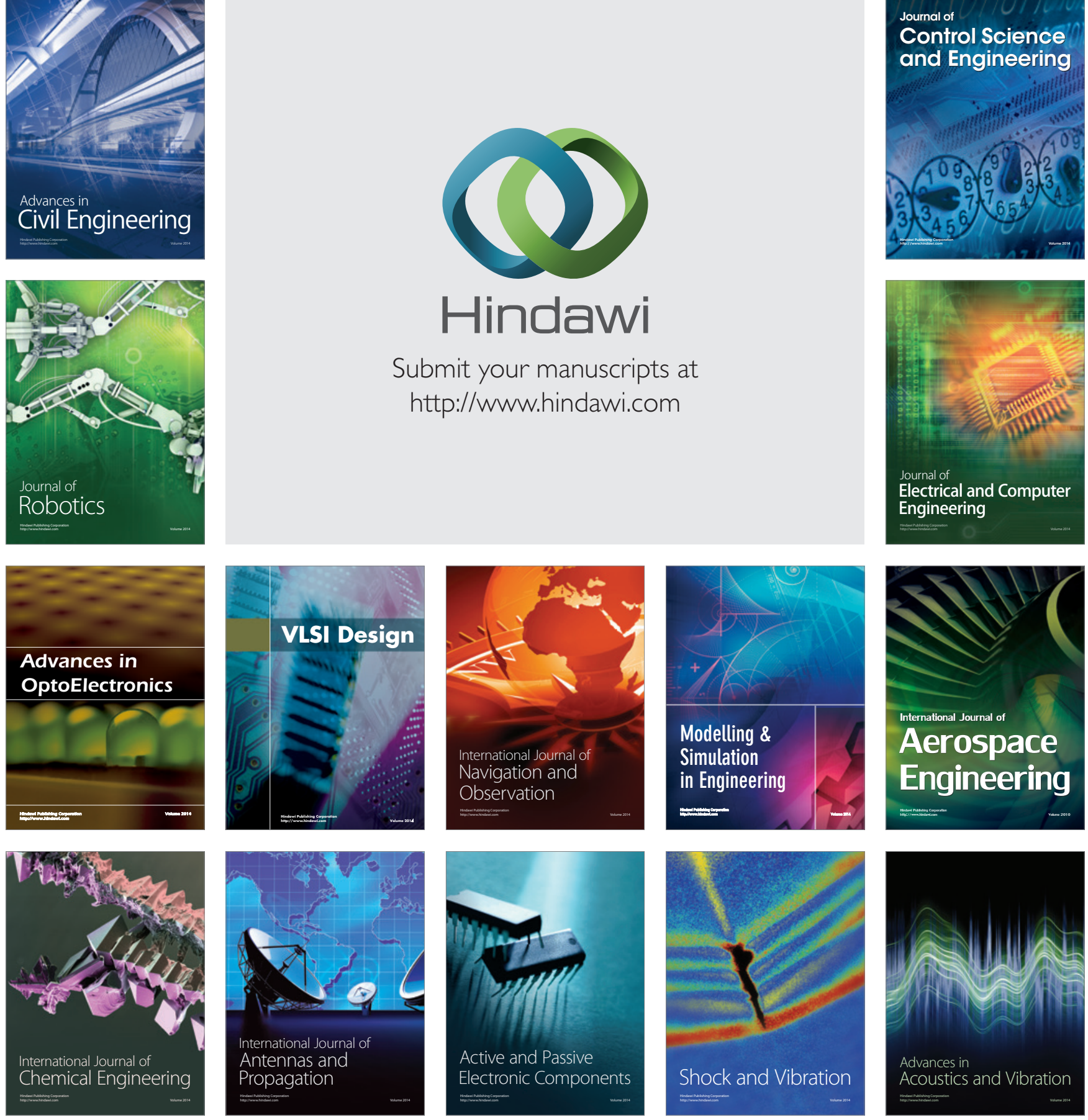